\title{
Kebaruan gaya ungkap dalam cerpen-cerpen berlatar budaya Bali
}

\author{
I Gusti Ayu Agung Mas Triadnyani \\ Universitas Udayana \\ Email: mtriadnyani@gmail.com
}

\begin{abstract}
There are many recurring social conflicts in Bali that originate in customs and cultures such as caste conflict, exclusion (kasepekang), and issues surrounding black magic. These conflicts are often used as inspiration for Balinese writers to write literary works such as novels and short stories. From the setting story on Balinese social conflict, it can be seen how public perception of the conflict and also how the author's style expresses social conflict through the art of literature. This article aims to find out the various social and cultural issues that inspire literary writers to write works of literature and how they deliver it so as to create works that educate and entertain. Two sets of short stories entitled Padi Dumadi (The Incarnation of Rice, 2007) by Adnyana Ole and Mandi Api (Bathed by Fire, 2008) by Aryantha Soethama, two of Bali's leading authors. The approach used in this study is structural approach that examines the elements of the text. Analysis shows that there is a tendency of Balinese authors to raise cultural issues with a new style of expression using the element of surprise at the ending of the story.
\end{abstract}

Keywords: ending of story, Balinese culture, literary style, element of surprise

\begin{abstract}
Abstrak
Ada banyak konflik sosial yang muncul berulang di Bali yang bersumber pada adat dan budaya seperti konflik kasta, pengucilan (kasepekang), dan isu ilmu hitam. Konflik-konflik tersebut sering dijadikan inspirasi bagi sastrawan Bali untuk menulis karya sastra seperti novel dan cerita pendek. Dari cerita berlatar belakang konflik sosial Bali itu dapat diketahui bagaimana persepsi masyarakat terhadap konflik dan juga bagaimana gaya pengarang mengungkapkan konflik sosial itu lewat seni sastra. Artikel ini bertujuan untuk mengetahui berbagai permasalahan sosial dan budaya yang menjadi inspirasi sastrawan menulis karya sastra
\end{abstract}


dan bagaimana cara mereka menyampaikannya sehingga tercipta karya-karya yang mendidik sekaligus menghibur. Dua kumpulan cerpen yang berjudul Padi Dumadi (2007) karya Adnyana Ole dan Mandi Api (2008) karya Aryantha Soethama, dua pengarang terkemuka Bali. Pendekatan yang digunakan adalah pendekatan struktural yang menelaah unsur-unsur di dalam teks. Analisis menunjukkan bahwa ada kecenderungan pengarang Bali untuk mengangkat persoalan budaya dengan gaya ungkap yang baru dengan mengunakan unsur kejutan di akhir cerita.

Kata kunci: akhir cerita, budaya Bali, gaya sastra, elemen kejutan

\section{Pendahuluan}

$\mathrm{D}$ alam khazanah kesusastraan dunia, termasuk sastra Indonesia, sering ditemukan nama tokoh, peristiwa, benda, atau sesuatu yang merujuk kepada karya sastra, kitab suci, sejarah, atau pun tradisi budaya sastrawannya. Karya tersebut dikatakan secara umum memiliki acuan. Acuan ini dapat digunakan sebagai kunci untuk memahami makna suatu karya sastra, dengan syarat acuan tersebut diketahui pembaca atau paling tidak dikenalnya. Apabila pembaca tidak memiliki pengetahuan yang sama tentang acuan seperti dimaksudkan oleh penulisnya, ia akan mengalami kesulitan untuk menafsirkan karya tersebut. Dengan kata lain, acuan menuntut pengetahuan yang luas dari pembacanya.

Kesulitan-kesulitan yang dihadapi pembaca dapat dipahami mengingat sebagian besar sastrawan cenderung memilih acuan yang sesuai dengan pengalaman estetiknya yang bersifat pribadi. Abrams (1981:8) menjelaskan bagaimana pengarang-pengarang modern sering memanfaatkan acuan yang sangat pribadi sifatnya dengan harapan beberapa orang saja yang mengetahui maknanya. Acuan tersebut diambil dari tradisi di mana sastrawan terlibat di dalamnya sebagai anggota masyarakat kebudayaan tertentu. Subagio Sastrowardoyo, misalnya, menulis sajak "Nawangwulan" yang merupakan salah satu mitos dalam kebudayaan Jawa, Amir Hamzah yang asli Sumatera menciptakan sajak berjudul "Hang Tuah" yang diilhami seorang tokoh dalam sejarah kerajaan Melayu, pun Ramadhan K.H. dengan "Priangan si Jelita" yang mengacu pada nama tempat di daerah Jawa Barat. 
Dalam kaitannya dengan kebudayaan Bali yang masyarakat pendukungnya dikenal kuat memegang tradisi, ada anggapan sastrawan Bali mengungkapkan persoalan-persoalan yang bersifat khas yang terdapat di dalam masyarakat itu. Anggapan di atas dapat dipahami karena sejak lahir mereka telah menyerap nilai-nilai budaya yang hidup dalam masyarakatnya dan konsep-konsep itu telah berakar dalam jiwa mereka. Hal ini sejalan dengan pendapat Lucien Goldmann yang mengemukakan adanya suatu 'world view' yang memengaruhi pandangan suatu masyarakat dalam suatu zaman (Laurenson, 1972:82) Sastrawan sebagai anggota masyarakat secara sengaja atau tidak menjelmakan pandangan dunia itu di dalam karyanya. Bagaimana ia menanggapi persoalan-persoalan sosial budaya yang tumbuh di dalam masyarakatnya.

Sejalan dengan perkembangan zaman, adat dan budaya pun turut menyesuaikan diri. Sebagai contoh tradisi kasepekang saat ini sudah mengalami berbagai perubahan (Diantha, 2009). Perkawinan antarkasta yang sering menimbulkan konflik juga telah mengalami penyempurnaan (Diantha, 2010). Gunawan (2014) bahkan telah meneliti berbagai perubahan sosial di Bali, khususnya di pedesaan. Perubahan-perubahan tersebut dilakukan untuk mencapai kehidupan yang lebih harmonis. Pengarang sebagai anggota masyarakat yang peka dengan berbagai perubahan sosial budaya yang terjadi, tidak akan melewatkan peristiwa ini. Mereka umumnya menulis peristiwa sosial budaya, seperti ngaben (kremasi), perbedaan kasta, kasepekang (pengucilan), pencaruan (pembersihan), salah pati (bunuh diri), cuntaka (kotor), tajen (sabung ayam), kerauhan (kesurupan), dan konflik tanah adat.

Agar karya-karya mereka tetap menarik karena membahas persoalan adat dan budaya yang sama, biasanya pengarang mencari cara baru untuk menuangkan idenya. Dengan demikian karyanya menarik diapresiasi karena unsur kebaruan (inovasi) yang diciptakannya. Beberapa pengarang menggunakan pemilihan akhir cerita (ending) yang menimbulkan kejutan. Karya-karya yang ditulis oleh Putu Wijaya sering memanfaatkan gaya ini demi pencapaian "surprise". Pengarang lain, seperti Oka Rusmini cenderung memilih diksi bernuansa negatif untuk menggambarkan adat dan budaya Bali, seperti terlihat dalam karyanya Tarian Bumi, Kenanga, dan Sagra, sedangkan Cok Sawitri menerapkan gaya dekonstruksi yang mengejutkan dalam mengolah watak tokoh maupun ide cerita 
(Triadnyani, 2014).

Artikel ini menyelidiki gaya ungkap Made Adnyana Ole di dalam kumpulan cerpen Padi Dumadi (2007) dan Gde Aryantha Soethama di dalam kumpulan cerpen Mandi Api (2008). Kajian terhadap kumpulan cerpen Mandi Api, di antaranya telah dilakukan oleh Hardiningtyas (2014), Rohmah (2008), Sujaya (2014). Namun, sampai saat ini belum ada penelitian yang memfokuskan pada elemen-elemen seperti motif, akhir cerita, mood tokoh, dan kejutan. Made Adnyana Ole dan Gde Aryantha Soethama dipilih karena memiliki kapasitas sebagai penulis cerpen yang handal, yang karya-karyanya antara lain dimuat dan masuk ke dalam cerpen pilihan Kompas. Keduanya adalah wartawan yang memiliki kesempatan luas dan intens dalam mengamati dinamika sosial Bali yang menjadi inspirasi karya mereka.

\section{Landasan teori dan metode}

Realitas yang dibangun oleh pengarang merupakan dunia tersendiri yang memiliki aturan-aturannya sendiri. Sebagai sebuah teks yang otonom, maka teks dapat didekati melalui dirinya sendiri. Cerpen merupakan salah satu genre sastra yang dibangun dari unsur-unsur utama di dalam sebuah karya sastra, seperti tema, tokoh, alur, dan latar. Salah satu unsur yang terdapat di dalam cerita adalah motif. Motif seringkali dikaitkan dengan tema. Di dalam tulisan ini motif adalah unsur yang menonjol di dalam cerita (bdk. Danandjaja, 1984:53). Motif dapat berupa sesuatu hal yang mendorong tokoh melakukan tindakan dan mengakibatkan serentetan peristiwa. Motif bermanfaat untuk melihat pergerakan alur cerita.

Berkaitan dengan alur (plot), akhir cerita (ending) merupakan elemen penting di dalam genre cerpen. Kermode (1967) secara khusus melakukan kajian tentang akhir cerita (ending). Penciptaan akhir cerita berkaitan dengan pertanyaan mendasar tentang awal dan akhir perjalanan manusia. Akhir cerita di dalam cerpen menjadi puncak harapan pembaca. Apakah tokoh berhasil melewati krisis atau justru semakin jauh terlibat konflik? Apakah tokoh berhasil mempertahankan sikap atau sebaliknya gagal dalam menghadapi ujian hidup? Secara tidak langsung pembaca memetik pelajaran dari cerita tersebut. Dengan demikian, akhir cerita penting untuk dikaji. Frye (1990:54) menguraikan adanya dua kecenderungan utama, yaitu cerita yang berakhir tragis atau yang berakhir konyol/ 
lucu. Dua persepsi ini merupakan akibat logis dari insiden-insiden yang diciptakan pengarang. Mood atau perasaan tokoh diakhir cerita juga dapat digambarkan dengan berbagai cara, antara lain, protes, mengeluh, mengejek, kesepian, getir, dan tenang. Adanya penggambaran perasaan tokoh dimaksudkan untuk melihat respon tokoh terhadap situasi akhir yang dihadapinya. Kejutan adalah aspek yang juga penting di dalam suatu cerita (Sudjiman, 1988: 37). Tanpa kejutan sebuah

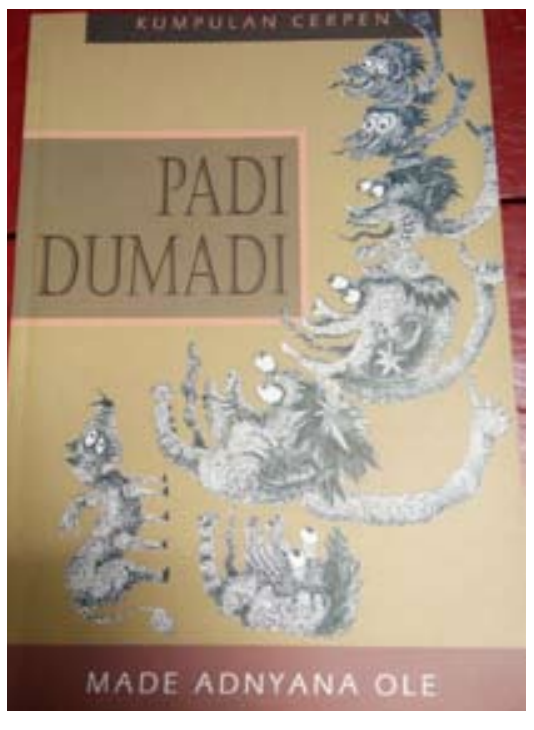
cerita akan terasa membosankan. Melalui unsur kejutan berbagai persoalan yang ditampilkan pengarang menjadi terasa baru.

Pertama-tama setiap cerpen diseleksi berdasarkan latar budaya yang dimilikinya. Cerpen yang dianalisis harus mempunyai acuan budaya Bali. Hal ini dilakukan untuk melihat apakah pengarang secara sadar menyampaikan persoalan sosial budaya Bali di dalam karyanya. Dengan demikian cerpen-cerpen yang tidak mengandung acuan budaya Bali tidak dianalisis. Langkah kedua menganalisis motif cerita. Ketiga, mencermati akhir cerita sekaligus mood tokoh. Langkah terakhir, melihat unsur kejutan yang terdapat di dalam cerpen. Beberapa insiden yang diciptakan pengarang boleh jadi menimbulkan kejutan bagi pembaca. Namun unsur kejutan ini juga tergantung pada seberapa luas wawasan dan tingkat kepekaan pembacanya. Keutuhan struktur cerpen dapat diketahui dari keterkaitan antarelemen tersebut.

\section{Tujuh cerpen Made Adnyana Ole}

Kumpulan cerpen Padi Dumadi berisi delapan cerpen, tetapi yang dipakai sebagai bahan kajian sebanyak tujuh cerpen. Satu cerpen tidak memenuhi syarat karena cerpen berjudul "Anak-anak Hilang di Kota Kecil Itu" tidak mengandung acuan budaya Bali. Analisis terhadap motif utama cerita, unsur kejutan, acuan budaya Bali, dan akhir cerita yang terdapat di dalam masing-masing cerpen dapat dilihat dalam tabel berikut. 
Tabel 1. Kumpulan cerpen Padi Dumadi

\begin{tabular}{|c|c|c|c|c|c|}
\hline No & $\begin{array}{l}\text { Judul Cer- } \\
\text { pen }\end{array}$ & Motif Utama & $\begin{array}{l}\text { Acuan } \\
\text { Budaya }\end{array}$ & Unsur Kejutan & $\begin{array}{l}\text { Akhir } \\
\text { Cerita }\end{array}$ \\
\hline 1. & $\begin{array}{l}\text { Istriku } \\
\text { Bernama } \\
\text { Sri }\end{array}$ & $\begin{array}{l}\text { Motif pelanggaran } \\
\text { (menjual sawah } \\
\text { warisan) }\end{array}$ & $\begin{array}{l}\text { Mitos } \\
\text { Dewi Sri }\end{array}$ & $\begin{array}{l}\text { Penggantian } \\
\text { nama semua } \\
\text { perempuan den- } \\
\text { gan nama Sri }\end{array}$ & $\begin{array}{l}\text { Konyol, } \\
\text { perasaan } \\
\text { tokoh bin- } \\
\text { gung }\end{array}$ \\
\hline 2. & $\begin{array}{l}\text { Capung } \\
\text { Hantu }\end{array}$ & $\begin{array}{l}\text { Motif pelanggaran } \\
\text { (mematahkan } \\
\text { sayap capung) }\end{array}$ & $\begin{array}{l}\text { Ritual } \\
\text { Pecaruan }\end{array}$ & $\begin{array}{l}\text { Tokoh cerita } \\
\text { (Dayu Bulan dan } \\
\text { si petani) meng- } \\
\text { hilang }\end{array}$ & $\begin{array}{l}\text { Tragis, } \\
\text { perasaan } \\
\text { tokoh sunyi }\end{array}$ \\
\hline 3. & $\begin{array}{l}\text { Ah, Cuma } \\
\text { Lelucon }\end{array}$ & $\begin{array}{l}\text { Motif keluguan } \\
\text { petani }\end{array}$ & $\begin{array}{l}\text { Ritual } \\
\text { bekerja }\end{array}$ & $\begin{array}{l}\text { Respon wartawan } \\
\text { yang mengang- } \\
\text { gap laporan } \\
\text { petani sebagai hal } \\
\text { sepele }\end{array}$ & $\begin{array}{l}\text { Konyol, } \\
\text { perasaan } \\
\text { tokoh } \\
\text { mengejek }\end{array}$ \\
\hline 4. & $\begin{array}{l}\text { Padi Du- } \\
\text { madi }\end{array}$ & $\begin{array}{l}\text { Motif pelanggaran } \\
\text { (berbohong asal } \\
\text { mula padi) }\end{array}$ & $\begin{array}{l}\text { Mitos } \\
\text { padi }\end{array}$ & $\begin{array}{l}\text { Jasad kakek seba- } \\
\text { gai pupuk benih } \\
\text { padi }\end{array}$ & $\begin{array}{l}\text { Tragis, } \\
\text { perasaan } \\
\text { tokoh getir }\end{array}$ \\
\hline 5. & $\begin{array}{l}\text { Pawang } \\
\text { Tikus }\end{array}$ & $\begin{array}{l}\text { Motif pelanggaran } \\
\text { (pemangku ber- } \\
\text { pura-pura kesuru- } \\
\text { pan) }\end{array}$ & $\begin{array}{l}\text { Mitos } \\
\text { jero } \\
\text { ketut }\end{array}$ & $\begin{array}{l}\text { Tikus minta } \\
\text { berdiskusi empat } \\
\text { mata }\end{array}$ & $\begin{array}{l}\text { Konyol, } \\
\text { perasaan } \\
\text { tokoh } \\
\text { getir }\end{array}$ \\
\hline 6. & $\begin{array}{l}\text { Pohon } \\
\text { Pedang } \\
\text { Kayu }\end{array}$ & $\begin{array}{l}\text { Motif pelanggaran } \\
\text { (melanggar wasiat) }\end{array}$ & Taksu & $\begin{array}{l}\text { Tokoh aku diam- } \\
\text { diam membong- } \\
\text { kar pot }\end{array}$ & $\begin{array}{l}\text { Tragis, } \\
\text { perasaan } \\
\text { tokoh men- } \\
\text { geluh }\end{array}$ \\
\hline 7. & $\begin{array}{l}\text { Rahasia } \\
\text { Gambuh }\end{array}$ & $\begin{array}{l}\text { Motif pelanggaran } \\
\text { (mengubah pakem } \\
\text { pertunjukan) }\end{array}$ & $\begin{array}{l}\text { Ritual } \\
\text { nyanjan }\end{array}$ & $\begin{array}{l}\text { Semua warga } \\
\text { kesurupan men- } \\
\text { jadi kelian } \\
\text { sekeha }\end{array}$ & $\begin{array}{l}\text { Tragis, } \\
\text { perasaan } \\
\text { tokoh } \\
\text { trance }\end{array}$ \\
\hline
\end{tabular}

\section{Cerpen-Cerpen Berakhir Tragis}

Cerpen "Padi Dumadi" berkisah tentang pertanyaan seorang cucu kepada kakeknya tentang asal mula padi. Pertanyaan yang sama ini turun temurun disampaikan oleh beberapa generasi sampai akhirnya tiba pada tokoh Wulaningrat Umadewi. Ia selalu bertanya kepada kakeknya, Nang Oman Pugur yang merupakan petani paling kuat di kampungnya (hlm. 38). Persoalannya, Nang Oman Pugur selalu menjawab pertanyaan cucunya dengan mengatakan bahwa asal benih adalah dari Tuhan. Ia tidak memiliki keberanian seperti kakek moyangnya untuk menjawab bahwa asal benih padi adalah dari kakekmu. 
Cerpen ini menyuarakan kekhawatiran pengarang terhadap memudarnya kesadaran orang, khususnya para petani tentang makna padi. Orang menanam padi sebatas untuk menghidupi diri dan keluarganya. Di dalam cerita itu digambarkan bagaimana Nang Oman Pugur menyerahkan segenap hidup dan matinya kepada si padi (hlm. 38). Bentuk penyerahan diri secara total inilah yang menjadi biang kerok kegusaran Nang Oman. Ia tidak berdaya menyaksikan anak dan cucunya ternyata tidak ada yang mewarisi kehebatannya di dalam bertani. Tidak ada yang lebih menyakitkan bagi seorang petani melihat kenyataan tersebut. Pada masa kini, situasi yang dialami Nang Oman Pugur boleh jadi terasa ironis. Sebab, sekarang ini jarang orang tua menginginkan anaknya menjadi petani. Mereka ingin anaknya menjadi pengusaha, dokter, atau pekerjaan lain yang dipandang lebih bergengsi.

Insiden yang dipakai untuk meningkatkan ketegangan cerita adalah pertanyaan cucu kepada kakeknya tentang asal mula padi. Ketegangan bertambah manakala si kakek kebingungan untuk menjawab pertanyaan yang sangat mudah itu. Kebingungan ini disebabkan oleh kebohongan yang diciptakannya sendiri. Ia berbohong soal asal mula padi. Asal mula padi yang tumbuh di sawah mereka sebenarnya adalah benih padi yang ditanam di atas kuburan kakek moyangnya. Jasad kakek yang telah menjadi pupuk bagi tumbuhnya benih padi merupakan unsur kejutan yang dipilih pengarang.

Cerpen "Rahasia Gambuh" mengisahkan seorang kelian sekeha (ketua kelompok) gambuh (seni pertunjukan klasik Bali) bernama Wak Miki. Ia memimpin sekeha ini sekaligus berperan sebagai Rahwana. Rahwana di dalam cerita ini digambarkan seperti pahlawan, sedangkan Rama justru takluk kepada Rahwana. Perubahan pakem pertunjukan ini menimbulkan persoalan. Kelian adatdanjuga pendeta mempermasalahkan perubahan iniyangdapat mengacaukan tatanan cerita lama (hlm. 77). Akhirnya, Wak Miki tewas diterjang peluru ketika sedang memainkan tokoh Rahwana. Dalam kisah ini juga diselipkan suatu upacara penggantian kelian sekeha (upacara nyanjan) yang mengandung unsur niskala. Orang yang menghirup busa yang keluar dari mulut kelian sekeha yang sedang meregang nyawa otomatis mewarisi kesaktiannya. Cerita berakhir secara mengejutkan, yaitu busa yang keluar dari mulut Wak Miki ternyata seperti asap yang kemudian dihirup oleh 
seluruh warga desa. Semua penduduk desa mendadak kerauhan. Mereka merasa menjadi kelian sekeha dan bisa memainkan tokoh Rahwana.

Cerpen ini boleh jadi dianggap sebagai sindiran keras terhadap para pelaku kesenian yang terpaku hanya pada satu pakem kesenian secara ketat. Upaya kreativitas dalam berkesenian dipandang sebagai perusakan terhadap aturan/tatanan baku. Tidak boleh ada upaya penyimpangan. Karena setiap penyimpangan ditengarai membawa dampak kehancuran.

Cerpen "Pohon Pedang Kayu" menceritakan kecerobohan tokoh aku yang melanggar wasiat sang kakek tentang warisan berupa pot. Pot itu diperoleh berkat persahabatan ayah si aku dengan seorang tentara Jepang. Pot itu tidak boleh dijual seberapa pun mahalnya dan tidak boleh dikeluarkan tanahnya. Semua orang melihatnya sebagai pohon yang memiliki aura tertentu sehingga mereka berani menawar pot itu dengan harga mahal. Yang membuat tokoh aku bingung dan penasaran adalah sebenarnya pot itu secara kasat mata hanya berisi tanah, namun secara tak kasat mata (niskala) disebutkan tumbuh pohon pedang kayu. Tokoh aku tidak percaya kepada tahayul. Ia pun membongkar pot tersebut dan walhasil hanya menemukan tanah semata. Ketika ia ingin menjualnya kembali, tidak ada satu pun yang mau membelinya. Pot itu sudah kehilangan "taksu." Maka, hanya penyesalan yang tertinggal. Di dalam kisah ini juga terdapat pelanggaran, yakni tindakan tokoh aku membongkar isi pot antik tersebut. Sebelumnya, ia telah diberi wasiat untuk tidak membongkar apa pun dari pot itu. Sebagaimana sebuah pelanggaran tentu memiliki hukumannya sendiri. Akhirnya, tokoh aku menyesal telah kehilangan 'taksu' dari benda antik itu.

Cerpen "Capung Hantu, Dayu Bulan dan lain-lain..." berkisah tentang tokoh saya yang disembunyikan oleh capung hantu karena telah melanggar larangan yakni mematahkan sayap capung. Dalam upaya mencari anaknya, tokoh ayah yang dipanggil "Ajik" diharuskan untuk menyumbat mata air di tengah hutan liar. Penyumbatan itu dilakukan agar air yang mengalir menuju tebing terhambat sehingga orang bisa menemukan goa yang berada di balik air terjun itu. Capung hutan diduga berumah di dalam goa tersebut. Untuk membebaskan anak tersebut ternyata diperlukan suatu upacara lagi yang disebut upacara pecaruan (hlm. 21). Akhirnya si anak berhasil ditemukan setelah dipenuhinya 
persyaratan yang rumit.

Dalam cerpen ini diselipkan unsur ritual pecaruan. Upacara pecaruan biasanya dilakukan masyarakat Bali untuk membersihkan dunia mikrokosmos dan makrokosmos. Jenis dan bentuk upacara ini bermacam-macam. Menurut Sudarsana (2001: 32), terminologi 'caru' berasal dari suku kata 'car' dan 'ru' yang berarti kala, musuh, atau kekotoran yang bersifat spiritual yang negatif dijadikan supaya suci demi terpeliharanya keseimbangan, keselarasan, dan keserasian buana agung (alam semesta) dan buana alit (manusia).

Di dalam cerpen tersebut terjadi pelanggaran terhadap larangan, yaitu mematahkan sayap capung. Apabila seseorang melanggar hal tersebut, ia akan dilarikan capung hantu ke tempat persembunyiannya. Mitos tersebut dipercaya masyarakat sekitar desa itu. Pelanggaran mitos dalam cerpen itu menguatkan keyakinan pembaca tentang adanya sebuah dunia lain yang tidak terjangkau logika. Upacara pecaruan yang - notabene refleksi dunia niskala-dilakukan sebagai syarat untuk menebus pelanggaran tersebut. Triadnyani (2017) menekankan kuatnya pengaruh dunia niskala (kekuatan irasional) ini di dalam karya-karya pengarang Bali sebagaimana tercermin dalam kehidupan masyarakatnya.

\section{Cerpen-cerpen berakhir konyol}

"Cerpen Istriku Bernama Sri" dapat dimaknai sebagai kritik pengarang terhadap tindakan sekelompok orang yang menjual sawah yang merupakan warisan leluhur. Akibatnya adalah sawah-sawah mendadak hilang. Sawah-sawah yang hilang milik rakyat itu ternyata berpindah ke halaman rumah milik tokoh aku. Peristiwa ini tergolong unsur kebolehjadian (plausibility). Kenney (dalam Sudjiman, 1988) menjelaskan bahwa kebolehjadian dalam suatu cerita harus dinilai berdasarkan ukuran yang ada di dalam karya itu sendiri. Secara kebetulan istri tokoh aku bernama Sri, yang boleh ditafsirkan pembaca sebagai Dewi Sri. Mitos tentang Dewi Sri berkembang di dalam masyarakat Bali sebagai dewi yang melindungi padi. Keberadaannya diyakini bahkan dipuja di pura subak.

Cerita pun diakhiri secara ironis melalui penggantian seluruh nama perempuan di kota tersebut menjadi Sri. "Semua tetanggaku, semua bawahanku di kantor, seluruh penduduk kota, bahkan mungkin selutuh negeri ini, ramai-ramai mengganti nama istrinya menjadi Sri..." 
(hlm. 35). Cara ini boleh dianggap sebagai unsur kejutan. Secara tidak langsung, penggantian nama ini memperlihatkan harapan pengarang terhadap eksistensi sawah yang sedikit demi sedikit tergusur.

Cerpen "Pawang Tikus" menggambarkan sebuah bencana yang menimpa sawah-sawah di Subak Buana Alit. Bencana itu berupa serangan ribuan tikus. Segala upaya dilakukan untuk membasmi tikus-tikus yang ganas itu, tetapi tak satu pun berhasil. Akhirnya, ada seorang pemangku pura yang sakti dan menguasai ilmu magis (hlm. 51) bernama Jero Mangku Macaling. Masyarakat meminta pertolongan jero mangku untuk mengatasi bencana ini. Setelah melakukan upacara ternyata ia pun tidak berhasil. Para petani marah mendapati kenyataan ini karena jero mangku itu adalah harapan mereka satu-satunya. Akhirnya terjadilah keributan, ia dipaksa untuk berdoa lagi. Karena tidak kuat menghadapi teror para petani, jero mangku pun berbohong dengan mengatakan bahwa tikus-tikus ingin berbicara empat mata dengan para petani. Petani tersinggung karena mereka tidak berani berbicara empat mata dengan tikus-tikus. Mereka marah dan pulang ke rumah masing-masing.

Melalui cerpen ini pengarang ingin menyampaikan kritik terhadap masyarakat Bali yang cenderung memilih mencari jalan keluar dengan cara niskala. Berbagai persoalan duniawi diatasi dengan cara spiritual. Sejak dahulu masyarakat Bali memiliki kepercayaan yang mendalam tentang keberadaan tikus-tikus ini. Tikus di Bali memiliki sebutan nama lain yakni jero ketut. Di Bali bahkan ada upacara pengabenan terhadap tikus. Tikus-tikus yang mati diupacarai agar tidak mengganggu hasil panen padi para petani.

Posisi pemangku adalah posisi suci dan dipercaya. Dalam kasus ini, pemangku telah melakukan pelanggaran. Ia digambarkan melakukan tindakan berbohong. Unsur kejutan di dalam cerpen ini adalah isi/pesan yang disampaikan pemangku kepada warga desa, yakni agar warga bersedia berdiskusi dengan para tikus secara empat mata. Pesan ini terdengar konyol, namun memiliki fungsinya di dalam cerita, yakni sebagai kontras terhadap profesi petani. Tugas petani adalah bekerja, bukan berdiskusi. Akhir cerita berhasil mengejutkan pembaca, sekaligus menyentil kesadaran pembacanya.

Cerpen "Ah, Cuma Lelucon kecil" mengisahkan seorang petani yang putus asa dengan kondisi rumah tangganya yang miskin. Ia 
kemudian menjual tanahnya yang terletak di lokasi yang strategis dan indah. Ia pun mendadak kaya raya, namun ia tidak tahu bagaimana cara mengelola uangnya dan tidak tahu harus bekerja apa. Akhirnya ia bekerja sebagai petani di sebuah hotel yang dahulu tanah itu adalah milik si petani. Hotel itu tetap mempertahankan sebagian besar sawahnya untuk dikelola sebagai bagian wisata terpadu. Ia lalu dipecat oleh atasannya yang merasa tersinggung karena mobil si petani diparkir di sebelah mobil

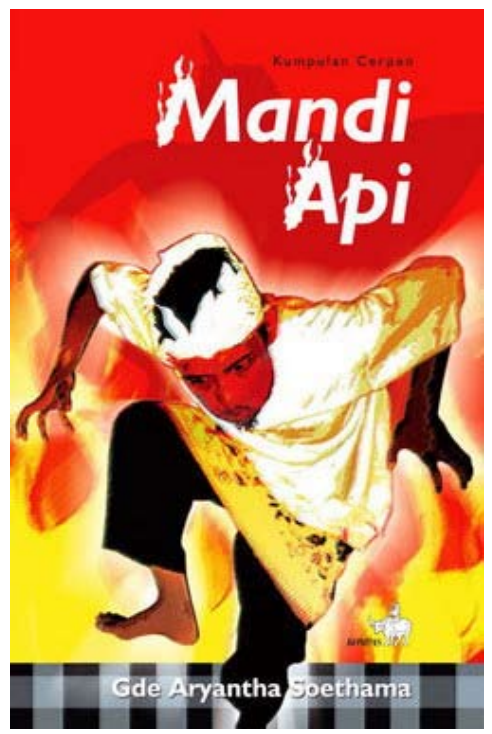
manajernya (hlm. 7). Atas pemecatan itu, si petani merasa telah diperlakukan tidak adil dan sewenangwenang. Si petani akhirnya mendatangi wartawan dan berharap agar berita tentang ketidakadilan dirinya ini dimuat di dalam surat kabar. Akhir cerpen ini cukup mengejutkan yakni respon si wartawan yang menganggap laporan si petani cuma lelucon.

Pengarang melakukan kritik terhadap orang Bali yang berduyun-duyun menjual tanahnya. Atas kondisi Bali yang carut marut ini, banyak orang menimpakan kesalahan pada globalisasi. Globalisasi telah menjadi kambing hitam. Para peneliti kebudayaan Bali, seperti Putra (2011) dan Vickers (2012) menyoroti kondisi Bali dan masyarakatnya yang mengalami perubahan, baik secara fisik dan mental. Melalui cerpen ini sekaligus juga dikritik gaya hidup orang Bali yang kaya mendadak. Mereka tidak tahu bagaimana caranya mengelola uang. Mereka hanya tahu caranya menghabiskan uang (hlm. 3). Kritik ini dibungkus sedemikian rupa sehingga yang tampak oleh pembaca adalah kekonyolan sikap si petani. Unsur kejutan di dalam cerpen tersebut dapat ditemui dalam diri si petani, yakni keluguannya. Ironisnya, keluguan si petani ditafsirkan sebagai lelucon oleh si wartawan.

\section{Sepuluh crpen Gde Aryantha Soethama}

Kumpulan Cerpen Mandi Api karya Gde Aryantha Soethama berisi dua puluh satu cerpen. Namun, cerpen yang dibahas di 
dalam penelitian ini hanya sepuluh, dengan pertimbangan adanya acuan budaya Bali yang digunakan sebagai latar cerita.

\section{Tabel 2. Analisis Kumpulan Cerpen Mandi Api}

\begin{tabular}{|c|c|c|c|c|c|}
\hline No & $\begin{array}{l}\text { Judul Cer- } \\
\text { pen }\end{array}$ & Motif Utama & $\begin{array}{l}\text { Acuan Bu- } \\
\text { daya }\end{array}$ & $\begin{array}{l}\text { Unsur Keju- } \\
\tan \end{array}$ & Akhir Cerita \\
\hline 1. & $\begin{array}{l}\text { Tembok } \\
\text { Puri }\end{array}$ & $\begin{array}{l}\text { Motif konflik ke- } \\
\text { luarga }\end{array}$ & $\begin{array}{l}\text {-Ritual metatah } \\
\text { (potong gigi) } \\
\text {-Kasta }\end{array}$ & $\begin{array}{l}\text { Pembaca } \\
\text { menunggu- } \\
\text { nunggu pilihan } \\
\text { Sumerti }\end{array}$ & $\begin{array}{l}\text { Tragis, } \\
\text { perasaan } \\
\text { tokoh getir }\end{array}$ \\
\hline 2. & $\begin{array}{l}\text { Terompong } \\
\text { Beruk }\end{array}$ & $\begin{array}{l}\text { Motif pelanggaran } \\
\text { (menjual terom- } \\
\text { pong tanpa izin) }\end{array}$ & $\begin{array}{l}\text {-Gamelan } \\
\text { khas dusun } \\
\text { Bangle } \\
\text {-Pujawali di } \\
\text { Pura Desa } \\
\end{array}$ & $\begin{array}{l}\text { Menjual } \\
\text { terompong } \\
\text { warisan }\end{array}$ & $\begin{array}{l}\text { Tragis, } \\
\text { perasaan } \\
\text { tokoh getir }\end{array}$ \\
\hline 3. & $\begin{array}{l}\text { Seekor } \\
\text { Ayam } \\
\text { Panggang }\end{array}$ & $\begin{array}{l}\text { Motif pelanggaran } \\
\text { (mengambil ayam } \\
\text { panggang diam- } \\
\text { diam) }\end{array}$ & $\begin{array}{l}\text {-Piodalan di } \\
\text { pura } \\
\text {-Sesaji; lung- } \\
\text { suran } \\
\text {-Mecaru } \\
\end{array}$ & $\begin{array}{l}\text { Kekerasan } \\
\text { hati Putu } \\
\text { Darmika men- } \\
\text { gadakan up- } \\
\text { acara mecaru } \\
\end{array}$ & $\begin{array}{l}\text { Konyol, } \\
\text { perasaan to- } \\
\text { koh jengkel }\end{array}$ \\
\hline 4. & Mandi Api & $\begin{array}{l}\text { Motif pelanggaran } \\
\text { (pura-pura kesu- } \\
\text { rupan) }\end{array}$ & -Kerauhan & $\begin{array}{l}\text { Pemangku } \\
\text { yang betul- } \\
\text { betul kesuru- } \\
\text { pan }\end{array}$ & $\begin{array}{l}\text { Tragis, } \\
\text { perasaan } \\
\text { tokoh pena- } \\
\text { saran }\end{array}$ \\
\hline 5. & $\begin{array}{l}\text { Kubur } \\
\text { Wayan } \\
\text { Tanggu }\end{array}$ & $\begin{array}{l}\text { Motif pelanggaran } \\
\text { (permusuhan den- } \\
\text { gan warga) }\end{array}$ & $\begin{array}{l}\text {-Kasepekang } \\
\text {-Tanah Adat }\end{array}$ & $\begin{array}{l}\text { Mengubur } \\
\text { mayat di da- } \\
\text { lam kamar }\end{array}$ & $\begin{array}{l}\text { Tragis, } \\
\text { perasaan to- } \\
\text { koh tenang }\end{array}$ \\
\hline 6. & Bohong & $\begin{array}{l}\text { Motif pelanggaran } \\
\text { (berbohong ten- } \\
\text { tang adanya sesaji) }\end{array}$ & $\begin{array}{l}\text {-Sesaji pati- } \\
\text { wangi }\end{array}$ & $\begin{array}{l}\text { Werti mengu- } \\
\text { capkan kebo- } \\
\text { hongan }\end{array}$ & \begin{tabular}{|l} 
Konyol, \\
perasaan \\
tokoh puas
\end{tabular} \\
\hline 7. & $\begin{array}{l}\text { Mati Salah } \\
\text { Pati }\end{array}$ & $\begin{array}{l}\text { Motif pelanggaran } \\
\text { (Kakek ingin } \\
\text { bunuh diri) }\end{array}$ & $\begin{array}{l}\text {-Ngaben } \\
\text {-Salah Pati }\end{array}$ & \begin{tabular}{|l|} 
Penabrak ada- \\
lah menantu- \\
nya
\end{tabular} & $\begin{array}{l}\text { Tragis, } \\
\text { perasaan } \\
\text { tokoh protes }\end{array}$ \\
\hline 8. & $\begin{array}{l}\text { Gumatat- } \\
\text { Gumitit }\end{array}$ & $\begin{array}{l}\text { Motif pelanggaran } \\
\text { (Balas dendam) }\end{array}$ & $\begin{array}{l}\text {-Wayang gu- } \\
\text { matat-gumitit } \\
\text {-Ngayah } \\
\text {-Meditasi }\end{array}$ & $\begin{array}{l}\text { Karpu mem- } \\
\text { bunuh Soroh }\end{array}$ & $\begin{array}{l}\text { Tragis, } \\
\text { perasaan to- } \\
\text { koh tenang }\end{array}$ \\
\hline 9. & Gerakan & $\begin{array}{l}\text { Motif pelanggaran } \\
\text { (Sembung berbo- } \\
\text { hong tidak mem- } \\
\text { bunuh }\end{array}$ & $\begin{array}{l}\text {-Reklamasi } \\
\text {-Melasti }\end{array}$ & \begin{tabular}{|l|} 
Mandor Bar- \\
gas dibunuh \\
diam-diam \\
oleh Sembung \\
\end{tabular} & $\begin{array}{l}\text { Tragis, } \\
\text { perasaan } \\
\text { tokoh protes }\end{array}$ \\
\hline 10. & Kulkul & $\begin{array}{l}\text { Motif pelanggaran } \\
\text { (warga berkonflik) }\end{array}$ & $\begin{array}{l}\text {-Suara Kulkul } \\
\text {-Cuntaka }\end{array}$ & $\begin{array}{l}\text { Ketika se- } \\
\text { orang tetua } \\
\text { meninggal, } \\
\text { kulkul lang- } \\
\text { sung dipukul }\end{array}$ & $\begin{array}{l}\text { Tragis, } \\
\text { perasaan } \\
\text { tokoh/warga } \\
\text { tenang }\end{array}$ \\
\hline
\end{tabular}




\section{Cerpen-cerpen berakhir tragis}

Cerpen pertama berjudul "Tembok Puri" yang bercerita tentang kebimbangan seorang perempuan bernama Kadek Sumerti untuk memilih upacara metatah (potong gigi) di rumah orang tuanya atau suaminya. Kedua pilihan itu membawa konsekuensi yang berat. Akhirnya pilihan jatuh pada suaminya dengan alasan Sumerti tidak mau dikucilkan dan tidak sanggup menjanda. Cerpen ini mengeksploitasi perbedaan kasta dan ritual dalam tradisi Bali. Kadek Sumerti berasal dari kasta sudra, sedangkan suaminya Anak Agung Ngurah Parwata adalah seorang brahmana. Suami dan keluarganya mengizinkan Sumerti untuk mengikuti upacara di rumah orang tua Sumerti, asalkan ia menempati posisi yang lebih tinggi dibandingkan saudara-saudaranya. Namun, orang tua Sumerti tidak menyetujui usul tersebut karena hal itu berarti penghinaan pada keluarga mereka. Keputusan yang mengejutkan baru dapat diketahui pada bagian akhir cerita. Cerita berakhir tragis karena Sumerti merasa sangat kecewa tidak dapat mengikuti upacara metatah bersama keluarganya.

Cerpen "Terompong Beruk" berkisah tentang nasib alat musik terompong beruk yang dijual kepada turis asing, padahal gamelan ini merupakan warisan turun temurun. Sekaha gamelan ini berasal dari Dusun Bangle, Kecamatan Karangasem dan kebetulan mendapat kesempatan tampil di PKB. Mereka biasanaya menabuh gamelan jika ada upacara pujawali (perayaan suci) di pura desa. Peristiwa ini menggambarkan betapa berkuasanya materi. Uang lebih berharga ketimbang nilai budaya warisan. Di dalam cerpen ini terdapat motif pelanggaran sekaligus unsur kejutan. Anggota sekaha gamelan menjual secara diam-diam tanpa sepengetahuan pimpinan, Mangku Rajeg. Namun, pengarang tidak mengeksploitasi pelanggaran ini lebih jauh, misalnya dengan memberikan hukuman atas pelanggaran ini. Yang digambarkan hanya perasaan getir tokohnya. Ia menyesal telah mengikuti kemauan orang kota.

Cerpen "Mandi Api" diawali dengan peristiwa kerauhan (trance) yang dilakukan seorang pemuda bernama Durma (h. 57). Lantas, narasi berpindah kepada insiden-insiden tentang kritik terhadap pembangunan hotel. Peristiwa kesurupan ini merupakan klimaks yang sengaja diciptakan pengarang sebagai alasan untuk diadakannya ritual mandi api. Ritual ini dilakukan untuk mengetes 
seseeorang yang kesurupan, apakah benar-benar kesurupan atau hanya berpura-pura. Tanpa diduga, seorang pemangku yang hadir pada saat itu mengalami kesurupan dan dialah yang terjun ke dalam ritual mandi api. Selamatlah pemuda itu. Unsur kejutan dihadirkan oleh pengarang. Di dalam kisah ini ada pelanggaran yang dilakukan oleh si pemuda. Ia berpura-pura kesurupan. Untunglah, ia tertolong oleh seorang pemangku.

Cerpen "Kubur Wayan Tanggu" merupakan sebuah kisah menarik yang memanfaatkan acuan lokal tentang kasepekang (pengucilan). Kasepekang merupakan tradisi pengucilan yang terjadi akibat warga melanggar aturan adat Bali (Diantha, 2009). Dalam kasus ini, Wayan Tanggu dan istrinya Luh Sasih dikucilkan karena berselisih tentang kepemilikan tanah. Ketika meninggal, mayat Wayan Tanggu tidak boleh dikubur di tanah adat tempat ia tinggal. Luh Sasih kebingungan, apalagi pedanda (pendeta brahmana) yang dimintai nasihat tidak bersedia membantu mencarikan solusi. Ironisnya, ia memilih mengubur suaminya di kamarnya sendiri. Dalam kisah ini terjadi pelanggaran karena menurut adat yang berlaku di mana pun tidak dibolehkan mengubur mayat di dalam rumah. Tindakan penguburan ini sekaligus merupakan unsur kejutan yang dibuat pengarang (lihat Sujaya, 2014). Anehnya, perasaan Luh Sasih justru merasa lebih tenang.

Cerpen "Mati Salah Pati" menceritakan upaya bunuh diri (salah pati) yang dilakukan seorang kakek karena takut menghadapi beban upacara ngaben untuk dirinya (h. 93). Si kakek membayangkan kesulitan yang dihadapi anak-anaknya untuk membiayai upacara tersebut. Ia bermaksud bunuh diri dengan cara ditabrak mobil. Ia berhasil melakukan bunuh diri, namun yang mengejutkan adalah yang menabraknya tak lain menantunya sendiri. Di dalam cerpen ini terdapat pelanggaran. Agama dan norma sosial tidak membolehkan orang melakukan bunuh diri. Cerita diakhiri dengan penyesalan putranya yang tak lain suami dari penabrak itu.

Cerpen "Gumatat-Gumitit" menyampaikan gagasan tentang balas dendam (h. 101). Motif dendam dipakai dalang Karpu untuk membunuh Soroh yang telah mengambil alih popularitas dan kehebatan dirinya. Karpu sebenarnya merupakan orang yang pertama kali menemukan wayang gumatat-gumitit, namun Soroh di hadapan orang banyak mengakui dialah sebagai penciptanya. Dengan dalih melakukan meditasi bersama di Bukit Tangsub, 
Karpu berhasil membunuh Soroh. Dalam cerpen ini pun terjadi pelanggaran berupa kebohongan disertai pembunuhan. Sampai akhir cerita, pembaca tidak menduga jika Karpu akan menghabisi nyawa Soroh. Pengarang mampu menggiring pembaca untuk tetap mempercayai tokoh Karpu sebagai orang yang pendiam dan baik.

Di dalam cerpen "Gerakan" pengarang menyampaikan kritik terhadap reklamasi pantai yang mengancam lokasi warga melakukan upacara melasti (h.113). Lantur dan Sembung sebagai pemuda yang antireklamasi menjalankan gerakan bawah tanah. Mereka menculik mandor Bargas dan mengikatnya di hutan. Dengan harapan, berita ini akan menciptakan kehebohan lalu pembangunan proyek dihentikan. Namun, terjadi kejutan ternyata Bargas tewas terbunuh. Di akhir cerita diketahui Sembung membunuhnya secara diam-diam. Padahal kedua pemuda itu telah bersepakat tidak akan melakukan pembunuhan. Dalam hal ini Sembung telah melakukan pelanggaran.

\section{Cerpen-cerpen berakhir konyol}

Di dalam cerpen "Seekor Ayam Panggang" pengarang menyampaikan kritik terhadap kekakuan seseorang dalam menjalankan suatu upacara. Cerita dilatarbelakangi oleh hilangnya seekor ayam panggang yang merupakan lauk utama dari sesaji ritual. Hilangnya ayam tersebut terjadi akibat ulah dua orang anak, padahal ayam tersebut sudah merupakan 'lungsuran'. Upacara sudah selesai dan ayam panggang itu sudah dihaturkan kepada dewa-dewa. Artinya, mereka sudah boleh menyantapnya. Sayangnya, mereka tidak berani menceritakan hal yang sebenarnya. Akibatnya keluarga besar memutuskan melakukan upacara mecaru untuk menetralisir dampak dari kehilangan tersebut. Meskipun, akhirnya keadaan yang sebenarnya diketahui, Putu Darmika tetap bersikeras mengadakan upacara, bahkan menghukum adiknya untuk menanggung seluruh biaya upacara. Ini merupakan unsur kejutan. Pembaca tidak menduga jika Putu Darmika tetap bersikeras.

Di dalam cerpen "Berbohong" terdapat acuan tentang sesaji patiwangi (h. 80). Ritual patiwangi biasa dilakukan terhadap seorang perempuan yang turun kastanya. Tokoh utama Werti diberi tugas oleh majikannya untuk mengamati keberadaan sesaji tersebut di dalam upacara penikahan Anak Agung Sagung Mirah dan Wayan Jirna. Keluarga Jirna tidak bersedia memenuhi permintaan 
keluarga bangsawan tersebut. Akhirnya, Werti berbohong soal sesaji tersebut. Hal ini dilakukan demi kebaikan kedua belah pihak. Motif pelanggaran berupa kebohongan dipakai pengarang untuk mengembangkan cerita. Unsur kejutan terjadi saat Werti berbohong. Ia mengucapkan kebohongan dengan sangat lancar.

Cerpen "Kulkul" melukiskan perdebatan tentang suara kulkul untuk orang mati. Gara-gara hal itu, masyarakat yang tadinya ramah digambarkan mendadak menjadi beringas (h. 124). Warga terbelah menjadi dua; satu mendukung tokoh adat Endek dan yang lainnya mendukung Songket. Perselisihan akhirnya dapat diatasi melalui faktor kebetulan sekaligus kejutan. Guru Sambat meninggal. Suara kulkul dipukul menuruti kebiasaan yang lama. Masyarakat pun menjadi tenang kembali.

\section{Simpulan}

Berdasarkan analisis kedua kumpulan cerpen di atas dapat disimpulkan. Pertama. motif utama cerita sebagian besar adalah motif pelanggaran. Motif pelanggaran biasanya terdapat di dalam cerita rakyat. Pelanggaran yang dilakukan oleh tokoh-tokoh menyebabkan pergerakan alur cerita. Cerita bergerak menuju klimaks dan dengan cepat diakhiri dengan kematian salah seorang tokoh atau hal-hal yang tragis. Pelanggaran terhadap aturan dan norma membawa konsekuensi. Tindakan pelanggaran sebagian besar dilakukan dengan cara berpura-pura atau berbohong.

Ada dua kecenderungan utama dalam cerpen-cerpen yang dianalisis, yaitu kecenderungan cerita yang berakhir tragis (sebelas cerpen) dan kecenderungan komikal (konyol) enam cerpen. Hal ini memperlihatkan kecenderungan yang menarik, yakni kedua pengarang lebih menyukai untuk menciptakan akhir cerita yang tragis.

Kedua, Made Adnyana Ole dan Gde Aryantha Soethama adalah dua dari beberapa pengarang Bali yang sudah dikenal di dunia sastra Indonesia. Mereka secara intens memanfaatkan latar sosial dan budaya Bali untuk menggarap cerpen-cerpennya. Latar budaya Bali yang diolah di dalam kumpulan cerpen Padi Dumadi, antara lain, ritual pecaruan, mitos Dewi Sri, mitos jero ketut, taksu, dan kerauhan (trance). Sementara, acuan budaya di dalam kumpulan cerpen Mandi Api, antara lain metatah, perbedaan kasta, piodalan, gamelan terompong beruk, sesaji, lungsuran, mecaru, kerauhan, kesepekang, tanah adat, patiwangi, ngaben, salah pati, wayang gumatat- 
gumitit, ngayah, dan melasti. Semua unsur-unsur lokal itu diolah dengan memanfaatkan motif pelanggaran yang menjadi pemicu pergerakan alur. Ketiga, unsur kejutan juga diolah sedemikian rupa, sehingga pembaca tidak dapat menduga apa yang akan ditampilkan oleh pengarang. Gaya ungkap seperti ini tentu saja menambah nilai kebaruan dari karya-karya mereka

\section{Implikasi}

Dari penelitian ini, ada satu hal yang menimbulkan pertanyaan yakni cerita yang berakhir tragis ternyata tidak selalu disertai dengan kegetiran atau kepahitan yang dialami oleh tokoh-tokohnya. Seringkali tokoh-tokoh lebih banyak digambarkan mengalami perasaan puas atau senang. Apa makna dari cara pengungkapan yang dibuat oleh pengarang ini?

Mengakhiri sebuah cerita secara tragis, namun sang tokoh digambarkan merasa puas. Tokoh digambarkan puas/senang melihat penderitaan orang lain. Padahal menurut adat dan norma, tokoh paling tidak turut merasa prihatin atau menyesali perbuatannya. Hal ini boleh jadi memperlihatkan kepribadian pengarang yang ambivalen (bdk. Sutherland, 1968). Di satu sisi pengarang merasa jenuh dengan segala kebobrokan yang terjadi di dunia ini, lalu menumpahkannya ke dalam cerita, lewat peristiwaperistiwa yang berakhir menyedihkan atau tragis (disadari atau tidak). Di sisi lain, rasa puas mereka salurkan lewat tokoh-tokohnya. Untuk pertanyaan yang tersisa ini, tentu saja diperlukan penelitian lain yang lebih mendalam.

\section{DAFTAR PUSTAKA}

Abrams, M.H. 1981. A Glossary of Literary Terms. Fourth Edition. New York.

Danandjaja, James. 1984. Folklor Indonesia: Ilmu Gosip, Dongeng, dan lain-lain. Jakarta: PT Grafiti Pers.

Diantha, Made Pasek, I Ketut Wirtha Griadhi, Wayan P. Windia. 2009. Kasepekang dalam Perspektif Hukum dan HAM. Denpasar: Bali Shanti.

Diantha, Made Pasek, I Gede Pasek Eka Wisanjaya. 2010. Kasta dalam Perspektif Hukum dan HAM. Denpasar: Udayana University Press.

Frye, Northrop. 1990. Anatomy of Critism: Four Essays. Princeton: Princeton University Press. 
Gunawan, D. Heryono. 2014. Perubahan Sosial di Pedesaan Bali: Dualitas, Kebangkitan Adat, dan Demokrasi Lokal. Tangerang: Marjin Kiri.

Hardiningtyas, Puji Retno. 2014. “Kelenturan Masyarakat Bali terhadap Modernitas dalam Kumpulan Cerpen Mandi Api." Jentera, Vol. 3, No. 2

Kermode, Frank. 1967. The Sense of An Ending: Studies in the Theory of Fiction. New York: Oxford University Press.

Laurenson, Diana and Alan Swingewood. 1972. The Sociology of Literature. London: Paladin

Ole, Made Adnyana. 2007. Padi Dumadi. Denpasar: Arti Foundation.

Nyeleneh, Ngaben Tikus Diikuti 93 ribu Jero Ketut. https://www. nasionalisme.co/8306-2/ diakses 10/08/2017.

Putra, I Nyoman Darma. 2011. A Literary Mirror: Balinese Reflections on Modernity and Identity in the Twentieth Century. Leiden: KITLV Press.

Rahmah. 2008. Potret Bali dalam Kumpulan Cerpen Mandi Api Karya Gde Aryantha Soethama. Skripsi S-1. Depok: Universitas Indonesia

Soethama, Gde Aryantha. 2008. Mandi Api. Jakarta: Gramedia Pustaka Utama.

Sudarsana, Ida Bagus. 2001. Ajaran Agama Hindu: Makna Upacara Bhuta Yadnya. Denpasar: Yayasan Dharma Acarya.

Sudjiman, Panuti. 1988. Memahami Cerita Rekaan. Jakarta: Pustaka Jaya.

Sujaya, I Made. 2014. “Wacana Pengucilan Sosial dalam Cerpen "Kubur Wayan Tanggu" Karya Gde Aryantha Soethama," dalam Stilistetika, Th III, Vol. 5, Nov.

Sutherland, Heather. 1968. "Pujangga Baru: Aspects of Indonesian Intellectual Life in the 1930s". Indonesia, 6, p. 106-127.

Triadnyani, I Gusti Ayu Agung Mas. 2014. Fenomena Rangda dan Pemaknaannya: Kajian Hermeneutika Ricoeur dalam Teks Calon Arang dan Novel Janda dari Jirah. Disertasi. Depok: Universitas Indonesia.

Triadnyani, I Gusti Ayu Agung Mas. 2017. "Rasionalitas dan Irasionalitas dalam Kumpulan Cerpen Penari Sanghyang." dalam Prosiding Seminar Bahasa Ibu. Denpasar: FIB Universitas Udayana.

Vickers, Adrian. 1996. Bali: A Paradise Created. Singapore: Periplus. 